\title{
FUNGSI MENGKUDU DALAM BANTEN PAMALI PADA UPACARA MECARU
}

\author{
Sang Ayu Made Yuliari \\ Program Studi Kesehatan Ayurweda, Fakultas Kesehatan, \\ Universitas Hindu Indonesia Denpasar \\ E-mail :yuliari120768@gmail.com
}

\begin{abstract}
Abstrak
Banten merupakan sarana bhakti bagi umat Hindu di Bali. Banten identik dengan Bali karena banten mempunyai daya tarik yang berifat magis sehingga turis asing banyak yang datang ke Bali.Salah satu banten tersebut adalah banten pamali. Berdasarkan hal itu maka tujuan penelitian adalah untuk mengetahui mengkudu sebagai sarana dalam banten pamali pada upacara mecaru, untuk mengetahui tata cara menyusun banten pamali dan untuk mengetahui fungsi mengkudu dalam banten pamali pada upacara mecaru. Untuk mendapatkan data digunakan metode porposif sampling dengan jenis penelitian kualitatif,untuk membedahnya memakai teori simbol dan Fungsionalisme struktural. Teori ini digunakan karena banten masih fungsional di masyarakat. Adapun hasil yang diperoleh 1)mengkudu adalah tanaman yang memiliki khasiat obat 2) tata cara menyusun banten pamali yaitu sebuah baki/tempeh diisi dengan taledan nasi kacang saur jajan buah/raka-raka, sate,lindung, capung, katak mengkudu bungsil,clebingkah yang bertanda tapak dara, sorohan alit dan canang sari ,3) mengkudu dalam banten pamali dapat berfungsi religius dan fungsi kesehatan.
\end{abstract}

Kata Kunci : Fungsi Mengkudu dan Banten Pamali

Banten is a devotional facility for Hindus in Bali. Banten is synonymous with Bali because Banten has a magical appeal so that many foreign tourists come to Bali. One of the bulls is Banten Pamali. Based on that, the purpose of the study was to find out Noni as a means in the Pamali pillow at the Mecaru ceremony, to find out the procedure for composing the Balinese pamali and to find out the function of Noni in Banten Pamali at the mecaru ceremony. To get the data used porposif sampling method with the type of qualitative research, to dissect it using symbol theory and structural functionalism. This theory is used because it is still functional in society. As for the results obtained 1) Noni is a plant that has medicinal properties 2) the procedure for preparing bantam pamali is a tray / tempeh filled with taledan nasi kacang saur snack fruit / raka-raka, satay, protected, dragonfly, petrified non-frog, clumsy marked tapak dara, sorohan alit and canang sari, 3) noni in banten pamali can function religiously and function health

Keywords: Noni Function and Banten Pamali 


\section{Pendahuluan}

Agama Hindu adalah agama yang kaya dengan kebudayaan sehingga orang luar menganggap bahwa agama Hindu adalah agama budaya. Disebut demikian karena yang tampak dalam keseharian adalah budayanya. Dalam pelaksanaannya agama Hindu di Bali memang lebih menonjol budaya karena nilai agama tersebut dibungkus oleh budaya itu sendiri. Agama dan budaya khususnya agama Hindu tidak dapat lepas dari budaya. Agama dan budaya di Bali merupakan satu kesatuan yang tidak dapat dipisahkan.Di mana ada budaya di sana terkandung nilai agama. Nilainilai yang terbungkus dalam budaya inilah yang perlu untuk diungkapkan, dikaji agar terungkap makna, maksud dan tujuan diselenggarakannya sebuah ritual.

Pelaksanaan upacara keagamaan di Bali menggunakan berbagai sarana atau upakara yang disebut dengan banten. Bantenidentik dengan wali/ Bali karena itu banten ini membawa daya tarik atau memiliki daya magis untuk menarik turis asing yang datang ke Bali. Dalam Agama Hindu mengenal lima jenis upacara yang disebut dengan panca yadnya.Panca yadnya terdri atas Dewa, Manusa, Pitra, Rsi dan Bhuta yadnya. Salahsatu dari panca yadnya tersebut adalah Bhuta yadnya. Upacara bhutayadnya seperti mecaru dari desa yang satu dengan desa yang lain upakaranya berbeda sesuai dengan desa kala dan patra. Perbedaan itu terjadi mungkin karena pemahaman atau interpretasi tentang bantenjuga berbeda. Di Bali mengenal istilah "celebingkah batan biu, gumi linggah ajak liyu”.'(Triguna,2011:76). Artinya dengan banyak orang dan dunia yang luas tentu mempunyai perbedaan satu dengan yang lain. Salah satu contoh adalah upakara atau sarana yang digunakan dalam melaksanakan kegiatan keagamaan bentuk upakaraatau sarananya beraneka ragam.Upakara yang beraneka ragam tersebut membangun sebuah keindahan dan mempunyai nilai seni. Belakangan ini demikian semaraknya umat melaksanakan upacara, ini merupakan pertanda yang baik namun, apakah setiap pelaksanaan upacara tersebut sudah sesuai dengan sastra? Upacara mecaru sebagai salah satu bentuk atau upaya pengendalian diri, karena dengan mecaru membuat supaya harmonis. Harmonis dalam pikiran, perkataan dan perbuatan. Tri kaya inilah yang harus diinisiasi melalui proses penyucian. Dalam geguritan Sucita Subudi disebutkan sebagaiberikut.

Sajeroning I trikaya, tepetang da manyampahin, ditu Sang Hyang Tri Purusa, linggayang sembah baktinin, idepang meraga jati, tunasin idep rahayu,anggon sarin atma raksa, sekalayang dina ratri, apang suluk, idepe tuara bimbang(1:7), Suka Yasa,2010:72). Artinya

Teks tersebut mengamanatkan bahwa tri kaya: pikiran, perkataan dan perbuatan adalah stana Tuhan. Oleh karena itu haruslah selalu disakralkan dengan jalan penyucian. Yang dimaksud Sang Hyang Tri Purusa dalam teks tersebut adalah Sang Hyang Brahma, Wisnu dan Iswara.Sang Hyang Brahma berstana pada badan (I:26). Sang Hyang Wisnu berstana pada kata (I:26). Dan Sang Hyang Iswara berstana pada pikiran (I:27). Beliaulah yang dipuja mohon supaya pikiran menjadi baik sebagai sari dalam menjaga jiwa, sewaktu malam bersujud dengan berkonsentrasi penuh, pikiran tidak bimbang.

Berdasarkan uraian teks tersebut dapat dipahami bahwa betapa sulitnya menyucikan trikaya.Dalam Sarasamuscaya disebutkan bahwa mempelajari tri kaya dan hubungannya dengan karma secara singkat dinyatakan karma itu timbul sebagai akibat dari pengendalian indriya. Tri kaya sebagai sebab timbulnya karma maka disebut Karmapatha.(1980:295). Salah satu bentuk pengendalain diri adalah melalui yadnya.Mecaru merupakan satu dari bagian panca yadnya yaitu bhutayadnya.Dalam upacara mecaru terdapat banten pamali. Banten pamaliini berisikan genteng yang sudah pecah(clebingkah) bahasa Bali. Pecahan genteng tersebut diisi tampak dara dan yang unik ada buah mengkudu. Pada Salinan Lontar EmpuLutuk Banten Caruada disebutkan nasi pamali jangkep namun, tidak ada disebutkan mengkudu(tibah) bahasa Bali. Disebutkan juga Banten caru eka sata tidak terdapat banten pamali. Banten pamali digunakan pada tingkatan yang lebih besar mulai dari panca sata(Pucuk,tt:1). Pada penelitian awal ditemukan bahwa kenyataan di masyarakat khususnya di Ubud Gianyar upacara mecaru ekasata atau abrumbunan menggunakan banten pamali. Pada banten pamali tersebut salah satu sarananya menggunakan mengkudu (tibah) sedangkan pada Empu LutukBanten Caru tidak ada diuraikan secara mendetail mengenai banten pamali.Banten pamali di Ubudsalah satu isinya mengkudu sedangkan di daerah lain seperti di 
Klungkung yang pernah diamati,banten pamali tersebut tidak berisi mengkudu. Isi banten pamali itu berisi buah bluluk/enau,buah kelapa yang masih sangat muda/bungsil dan tibah/mengkudu.Mengapa tibah sebagai salah satu sarananya sedangkan ada buah yang lainnya seperti jambu air, jambu biji yang rasanya lebih manis? Tibah yang matang rasanya tidak enak dan berbau anyir, ada apakah dengan tibah? Berdasarkan hal itu maka perlu diadakan penelitian lebih lanjut agar terungkap fungsi mengkudu dalam banten tersebut.

\section{Metode Penelitian}

Penelitian ini menggunakan metode porposif sampling untuk memperoleh data yang sesuai dengan tujuan penelitian. Adapun pendekatannya memakai pendekatan agama dengan jenis penelitian kualitatif yaitu menyusun kata-kata yang dirangkai menjadi suatu kalimat secara deskriptif dari hasil wawancara di lapangan.

\section{a. Kajian Pustaka}

Wiana (2007) dalam buku yang berjudul Tri Hita Karana Menurut Konsep Hindu menyebutkan bahwa banten dalam kehidupan beragama Hindu di Bali merupakan unsur yang amat dominan sebagai sarana dalam melakukan ritual keagamaan Hindu. Dalam banten tersebut ada nilai-nilai sosial religius. Sarana upacara yajnadalam kehidupan beragama Hindu di Bali disebut dengan banten.Banten sebagai visualisasi yang melukiskan hubungan manusia dengan Tuhan melalui bhakti, hubungan harmonis manusia dengan sesama manusia melalui punia, hubungan harmonis manusia dengan lingkungannya berdasarkan asih,punia dan bhakti. Ketiga itu mencerminkan suksmaning banten. Dalam Lontar yajna Prakerti disebutkan sebagaiberikut."Sehananing bebanten pinaka raganta twi, pinaka warna rupaning Ida Bhatara, pinaka Anda Bhuwana". Artinya semua bebanten adalah lambang dirimu sendiri,lambang kemahakuasaan Tuhan dan lambang bhuwana isi alam semesta.

Gorda(2004) dalam buku yang berjudul Membudayakan Kerja Berdasarkan Dharma disebutkan lima persembahan utama. Kelima persembahan itu adalah:1) persembahan kepada Tuhan (Deva Yajna),2) persembahan kepada leluhur(pitra Yajna), 3) Persembahan kepada oraang suci(Rsi Yajna), 4) Persembahan kepada sesama manusia (Manusa Yajna) dan 5) persembahan kepada alam sekitar (bhuta yajna).

Wiana (1997) dalam buku yang berjudul Beragama Bukan Hanya Di Pura menyebutkanbahwa tiga hutang dibayar dengan panca yajna.Bhuta yajna adalah memelihara kesejahteraan alam lingkungan yang merupakan anugerah untuk tempat dan sarana kehidupan semua makhluk. Sejalan dengan Wiana,Sivananda (1993) mengungkapkan empat jalan untuk mewujudkan Tuhan (Karma, Bhakti, Raja dan Jnana yoga). Wiana (2009) dalam buku yang berjudul Makna Hari Raya Hindu menyebutkan bahwa Tawur Kesanga tergolong upacara Bhuta Yajna. Upacara bhuta yajna disebut juga mecaru.

Anom (tt) dalam alih aksara Lontar yang berjudul Pupulan Indik Caru Lan Tawur disebutkan bahwa banten pamali digunakan bilamana terdapat keganjilan dalam hidup seperti karang panes, caru umah cacad, kadurmangalan dan lain sebagainya. Pada banten tersebut ada menggunakan daun mengkudu/don tibah.Sejalan dengan Anom dalam alih aksara lontar Bhama Kertih (Pemprop Bali,2000) disebutkan tentang pamali. Selanjutnya Pucuk(tt) dalam salinan lontar Empu Lutuk Banten Caru, banten pamali tersebut digunakan pada tingkatan yang lebih besar mulai dari Panca sata. Dalam lontar Empu Lutuk tersebut meskipun tidak diuraikan secara jelas tentang isi dari banten pamali itu, di masyarakat khususnya di Ubud banten pamali itu salah satunya berisi buah mengkudu/tibah. Mengkudu sudah diteliti secara ilmiah kurang lebih tahun 1950, Jurnal Pasifc Science melaporkan bahwa buah mengkudu menunjukkan sifat anti bakteri terhadap.pyrogenis,Paeroginosa dan bahkan E,coli yang membahayakan kesehatan itu. Pada tahun 1993 Jurnal Cancer Letter melaporkan bahwa beberapa peneliti dari Keio University dan The Institut of BiomedicalScience di Jepang yang melakukan riset terhadap 500 jenis tanaman mengklaim bahwa menemukan zat-zat anti kanker yang terkandung dalam mengkudu. Sudarsana (tt) dalam diktat yang berjudul Himpunan 
Tetandingan Upakara Yadnyadisebutkan tentang cara merangkai banten caru.

\section{b. Fungsi}

Pengertian fungsi dalam Kamus Besar bahasa Indonesia (2008:400) yaitu (1) kegunaan suatu hal, (2) jabatan atau pekerjaan sedangkan berfungsi artinya berkedudukan, bertugas, kemampuan yang dimiliki oleh seseorang yang sesuai denganpekerjaannya/tugasnya dan fungsionalisasi artinya menjadikan berfungsi. Fungsi dalam Kamus Filsafat berasal dari bahasa latin yaitu functio, fungi (menjalankan, melaksanakan) (Bagus,2005:270). Adapun pengertian fungsi dalam penelitian ini adalah kegunaan manfaat mengkudu dalam banten pamali pada upacara mecaru.

\section{c. Mengkudu (Morinda Citrifolia)}

Mengkudu dalam Kamus Besar Indonesia Kontemporer disebutkan bahwa mengkudu itu adalah pohon yang buahnya dapat dijadikan obat peluruh kencing, untuk menurunkan tekanan darah tinggi. Daunnya dapat dipakai sebagai obat sakit perut, akar, kulit dan batang digunakan sebagai pembatikan. (Yeni Salim, 2002 : 961). Sejalan dengan Yeni dan peter Salim dalam Kamus Besar Bahasa Indonesia Pusat Bahasa mengkudu itu adalah pohon yang banyak manfaatnya tergolong suku Rubiaciae buahnya berwarna putih, keruh, berbentuk bulat sampai bulat telur, permukaannya berbenjol-benjol, berbiji banyak, daging buahnya yang masak lunak, banyak mengandung air, rasanya agakmasam, digunakan sebagai obat peluruh kencing, dapat menurunkan tekanan darah tinggi, batangnya mengandung zat warna merah sebagai pembatikan (Tiem penyusun, 2008:900). Buah mengkudu ini diteliti secara ilmiah kurang lebih tahun 1950,dilaporkan bahwa buah mengkudu menunjukkan sifat anti bakteri terhadap $M$ pyrogenes dan $E$ coli yang membahayakan kesehatan. Pada tahun 1993, Jurnal Cancer Letter melaporkan bahwa mengkudu mengandung zat-zat anti kanker.Di samping itu manfaat lain dari buah mengkudu sudah dibuktikan secara ilmiah yaitu untuk meningkatkan daya tahan tubuh, menormalkan tekanan darah dan buah mengkudu membantu pemulihan sejumlah penyakit seperti: gangguan pencernaan, diabetes, nyeri, alergi dan lain sebagainyaa. Tanaman ini juga mengandung berbagai vitamin, mineral, enzim, alkaloid kafaktor dan sterol tumbuhan yang terbentuk secara alami(Suwandi,tt:3839).Tibah dalam Kamus Bali Indonesia adalah nama pohon yang buahnya berbiji banyak dapat dipergunakan rujak (Anonim,2005:775). Hakimah,2013:103) menyebutkan bahwa mengkudu mempunyai khasiat melancarkan metabolisme tubuh, menenangkan dan menstabilkan tekanan darah,kolestrol, melancarkan kencing, meyembuhkan asam urat dan banyak lagi manfaat mengkudu. Yang dimaksud mengkudu dalam penelitian ini adalah pohon yang buahnya berbiji banyak dapat bermaanfaat untuk kesehatan, menormalkan dan mengharmoniskan serta keseimbangan tubuh.

\section{d. Banten Pamali.}

Kata Banten dalam Kamus Bali Indonesia mempunyai arti persembahan dalam upacara keagamaan, banten artinya suguhi sajen, bantenin yaitu disuguhinya sajen, bantenanga yaitu dipersembahkannya sajen (Anonim,2005:68). Banten Pamali: sarana slanggi 1, ajuman 1 tanding,mantra..Ih sira sang unyuk api, aywa sira masur ring...karyaningsun, teka inih,iki haturan sira tanggapen telas.(Bangli,2006:86). Pemali adalah sebutan orang yang nakal, pemalinan adalah nama penyakit pada punggung. (Anandakusuma,1986:142). Pemali dalam Kamus Bali Indonesia artinya pemali, pe-mali-an artinya penyakit karena pemali(Anonim,2005 :549).Pemali berasal dari kata pa-mali. Mali adalah ungkapan untuk wanita. Sedangkan Mala ungkapan untuk lakilaki. Mala berarti leteh, kotor, tidak suci. Pemali adalah suatu penyakit yang gejalanya sakit di tubuh bagian dalam seperti ditusuktusuk. Disebutkan bahwa sakit ini akibat adanya angin atau udara yang terjepit di dalam tubuh, terutama di daerah tulang rusuk dekat perut di sebelah kiri atau kanan, di daerah peliokan ( Nala,1993 : 200). Jadi yang dimaksud banten pamali dalam penelitian ini adalah sebuah persembahan atau banten untuk menetralisir kekotoran /leteh dalam diri maupun lingkungan rumah/tempat tingal sehingga menjadi harmonis kembali.

\section{e. Mecaru}

Kata mecaru berasal dari kata caru mendapat awalan me sehingga menjadi mecaru. Caru artinya harmonis atau cantik. Tujuan dari upacara bhuta yajnal mecaruadalah mengharmoniskan hubungaan dengan alam lingkungan. Dalam Lontar 
Agastya Parwa disebutkan bahwa "Bhuta yajna ngarania taur muang kapujan ring tuwuh" yang artinya bhuta yajna adalah mengembalikan dan melestarikan tumbuhtumbuhan (Wiana,2009:44).Caru dalam bahasa Sanskerta tergolong (1)ajektif berarti indah, bagus, (2) korban ,sajian, tempayan, (Tiem penyusun,2001:157).Upakara caru mempunyai fungsi untuk menetralisir kekuatan-kekuatan alam bersifat buruk yang dapat menghilangkan keseimbangan hidup antara manusia dengan alam sekitarnya, sehingga muncul di dunia ini bermacammacam kejadian dapat menyengsarakan hidup manusia (Sudarsana,tt :39). Jadi Mecaru dalam penelitian ini adalah mengembalikan dan menetralisir kekuatan-kekuataan alam yang bersifat buruk sehingga terpelihara keseimbangan.

\section{f. Landasan Teori Teori Simbol}

Cassier (dalam Tri Guna,2000:3) menyatakan bahwa simbol merupakan bagian dari dunia makna, maka manusia yang berfungsi sebagai digsinator. Oleh karena itu simbol tidak memiliki kenyataan fisik tetapi hanya memiliki nilai fungsional. Simbol tidak hanya cognitive tetapi juga emotive. Selanjutnya Titib (2003:66) menjelaskan bahwa simbol keagamaan mampu mengungkapkan suatu modalitas dari yang nyata atau suatu struktur dunia yang tidak nampak pada pengalaman langsung. Tri Guna (2000:35) menyatakan bahwa ada empat peringkat simbol yaitu:

(1) Simbol kontruksi yang berbentuk kepercayaanbiasanya merupakan inti dari agama

(2) Simbol evaluasi berupa penilaian moral yang sarat dengan nilai, norma dan aturan

(3) Simbol kognisi berupa pengetahuan yang dimanfaatkan manusia untuk memperoleh pengetahuan tentang realitas dan keteraturan agar manusia lebih memahami lingkungannya.

(4) Simbol ekspresi berupa pengungkapan perasaan. (Candra,2016:32).

Teori symbol digunakan karena dapat dimanfaatkan manusia untuk memperoleh pengetahuan dibalik yang tersurat pada sebuah banten.Banten merupakan sebuah symbol yang memiliki bentuk, fungsi dan makna. Banten adalah sebagai pengejawantahan Tuhan atau manifestasi Tuhan. Tuhan yang nirgunasangat sulit untuk dipahami oleh manusia yang awam karena Tuhan/Ida Sang Hyang Widhi tidak berwujud tidak mempunyai bentuk oleh karena itu manusia atau pemujanya memberikan wujud sesuai dengan kemampuannya.Tuhan yang nirguna itu diberi sifat sehingga memudahkan untuk memahaminya. Tuhan yang bersifat itu adalah dalam wujud Saguna. Tuhan yang Saguna ini memiliki sifat dengan bersifat maka mudah untuk dimengerti dan dipahami oleh umat manusia. Melalui Banten pamaliini manusia (umat Hindu ) berharap dapat bercengkerama dengan Tuhan/Sang Hyang Widhi. Sebagai ungkapan terima kasih juga diwujudkan dalam bentuk banten. Umat Hindu di Bali untuk mengungkapkan rasa senang, sedih, bersalah juga melalui sebuah banten. Dengan banten atau persembahan umat manusia merasa selalu dekat berada di sampingNya. Mengkudu dalam banten pamali pada upacara mecarutersebut adalah sebuah simbol yang mempunyai nilai fungsional. Mengkudu yang digunakan dalam banten pamali sebagai salah satu sarana atau simbol, dengan harapan manusia selalu menjaga keseimbangan baik terhadap diri sendiri juga terhadap lingkungan sehingga terwujud keharmonisan. Dengan demikian banten ini dapat diungkap menggunakan teori simbol.

\section{Teori Fungsionalisme Struktural}

Teori fungsionalisme struktural menekankan keteraturan (order), konsep utamanya adalah fungsi, fungsi manifes, fungsi laten dan keseimbangan (equilibrium). Menurut teori ini masyarakat merupakan suatu sistem sosial yang terdiri atas bagian-bagian atau elemen yang saling bergantung satu sama lain, tetapi juga system social dianggap terdiri atas individu-individu yang saling berhubungan (membentuk relasi social). Agar suatu system terintergrasi dan stabil individuindividu yang menjadi bagian dari system tersebut memberi dukungan keberadaan nilainilai umum yang berlaku di dalamnya.(Usman,2012:53).Perubahan yang terjadi pada satu bagian akan membawa perubahan pula terhadap bagian yang lain. Asumsi dasarnya adalah setiap struktur dalam sistem sosial, fungsional terhadap yang lainnya. Sebaliknya kalau tidak fungsional maka struktur itu tidak ada dan akan hilang dengan sendirinya(Ritzer,2004 : 21).Agama Hindu mempunyai tiga kerangka dasar sebagai 
pedoman dalam melaksanakan keagamaannya. Ketiga kerangka tersebut adalah Tattwa,Susila dan Upakara/upacara. Agama Hindu di Bali dalam melaksanakan kegiatan keagamaannya yang tampak adalah upakara/ upacara yajna, sehingga banyak sekali bentuk upakara/upacara yang diselenggarakan oleh masyarakat. Ajaran Agama Hindu secara sederhana dibahasakan atau dituangkan ke dalam upakara/upacara yang dikemas oleh budaya dan sebagai wadahnya adalah adat.

Banten pamali pada upacara mecaru yang dilaksanakan oleh masyarakat merupakan suatu sistem keyakinan, budaya (tradisi Bali ). Salah satu sistem budaya Bali (tradisi Bali) yaitu Fungsi mengkudu dalam banten pamali pada upacara mecaru berwujud pikiran dan gagasan manusia, menyangkut keyakinan serta konsepsi manusia tentang Tuhan beserta manifestasinya. Sistem budaya Hindu Bali yang menyangkut sistem nilai, relegi, gaib dan magis menjadi pedoman atau pola bagi perilaku masyarakat dalam memperlakukan berbagai jenis banten dengan sarana pendukung lainnya. Salah satu sarana yang digunakan adalah mengkudu dalam banten pamali pada upacara mecaru sehingga berfungsi sebagai persembahan/fungsi religious dan fungsi sebagai obat dan mengharmoniskan hubungan antara manusia dengan lingkungannya. Dengan demikian berfungsi atau tidak berfungsinya mengkudu dalam banten pamali pada upacara mecaru akan memberikan umpan balik positif atau negatif terhadap masyarakat dan sistem budaya Bali. Artinya jika mengkudu dalam banten pamali pada upacara mecaru tersebut tidak memberikan fungsi, maka kemungkinan sistem budaya akan berubah atau hilang dengan sendirinya.

\section{Pembahasan}

\section{a. Mengkudu Sebagai Sarana dalam Banten Pamali}

Berdasarkan teori symbol yang diungkapkan oleh Tri Guna bahwasimbol kontruksi yang berbentuk kepercayaan biasanya merupakan inti dari agama. Kepercayaan umat Hindu di Bali adalah apabila sudah melaksanakan upacara hal itu diyakini hidup menjadi lebih baik. Banten merupakan salah satu bentuk pengungkapan perasaan melalui bhakti dengan sarana banten yang dilakukan oleh orang awam,tingkat jnananya belum sampai ke raja yoga.Banten sebagai simbol ekspresi berupa pengungkapan perasaan. (Candra,2016:32).

Banten pamali merupakan simbolis yang mengandung nilai-nilai kebenaran khususnya pada sarana yang digunakan yaitu mengkudu. Mengkudu sebagai salah satu sarana dalam banten pamali memberikan makna bahwa buah tersebut mampu menetralisir keadaan yang tidak baik pada diri manusia dan secara keseluruhan banten pamali memberikan makna keharmonisan terhadap lingkungan dimana bertempat tinggal. Sejalan dengan teori tersebut, berdasarkan hasil penelitian bahwa mengkudu dipakai sebagai salah satu sarana dalam banten pamalidi Ubud karena buah mengkudu dapat bermanfaat sebagai minuman yang berkhasiat obat seperti dibuat dalam bentuk rujak tibah dan ada juga dibuat loloh serta sebagai camilan sehabis makan oleh orang tua zaman dahulu.Rujak atau loloh mengkudu setiap hari diminum mengakibatkan badan terasa seger dan bugar karena khasiat yang dimiliki buah mengkudu tersebut meskipun tidak tahu kandungan apa yang terdapat pada buah mengkudu tetapi meyakini bahwa buah tersebut dapat menyehatkan badan. Hal ini sejalan dengan Neil Solomon yang melakukan survey terhadap 800 pengguna sari buah mengkudu dengan melibatkan 40 dokterdan praktisi medis lainnya menunjukkan bahwa sari buah mengkudu membantu pemulihan sejumlah penyakit antara lain: kanker, penyakit jantung, gangguan pencernaan, diabetes, strok dan sejumlah penyakit lain seperti lesu, kegemukan, tekanan darah tinggi, artritis, nyeri, alergi dan lain sebagainya. (Suwandi.tt.40).Dokter Schechter( Institut Pengobatan Alami di California) menghasilkan data-data penting tentang kemampuan sari buah mengkudu diantaranya yaitu merangsang produksi sel T system kekebalan tubuh. Sel T berperan penting dalam melawan penyakit, memperkuat system kekebalan tubuh terutama makrofaset dan limfosit dari sel darah putih, menunjukkan efek anti bakteri mempunyai efek anti rasa sakit/nyeri/analgesic dan menghambat pertumbuhan sel-sel pra kanker/tumor yaitu dengan kemampuannya menormalkan yang abnormal(Suwandi.tt.43). Berdasarkan riset ilmiah senyawa di dalam buah mengkudu memiliki khasiat untuk merangsang respon pembentukan kekebalan tubuh., membersihkan darah,mengatur fungsi sel rusak dan menghambat tumor. Fitokimia (zat-zat kimia) alami yang terdapat pada 
tumbuh - tumbuhan memiliki khasiat untuk pencegahan penyakit dan kaya akan kandungan antioksidan. Mengkudu mempunyai spectrum fitokimia yang sangat luas, beberapa diantaranya hanya terdapat di dalam mengkudu (Suwandi,tt.56).

\section{b. Tata Cara Menyusun Banten Pamali}

Penyusunan banten pamali dengan menggunakan teori fungsionalisme structural , inti dari teori tersebut adalah apabila tidak fungsional maka dengan sendirinya budaya tersebut akan hilang. Melalui upacara umat Hindu di Bali mendekatkan diri dengan Tuhan/Ida SangHyang Widhi sebagai bentuk pengamalan ajaran agama. Banten sarat dengan symbol dan makna. (Lontar Yadnya Prakerti dalam Wiana) disebutkan bahwa banten pinaka warna rupaning Ida bhatara. Banten juga melambangkan Kemahakuasaan Tuhan. Ada banyak banten yang melambangkan Kemahakuasaan Tuhan seperti canang. Canang melambangkan Tri Murti karena isi dari canang tersebut adalah sirih,pinang dan kapur diikat menjadi satu disebut dengan porosan. Porosan itulah yang melambangkan Dewa Tri Murti. Sirih lambing Dewa Wisnu,pinanglambang Dewa Brahma dan kapur lambang Dewa Siwa. Sebesar apapun banten harus dilengkapi dengan sebuah canang. Canang dalam pemujaan Hindu adalah untuk mendapatkan tuntunan dari Tuhan dalam manifestasinya sebagai Hyang Tri Murti.Selain berisi porosan canang juga dibentuk dengan berbagai reringgitan dan tetuwasan. Dalam lontar Yadnya Prakrti juga disebutkan bahwa reringgitan dan tetuwasan melambangkan kelanggengan meyadnya, bunga melambangkan kesucian dan ketulusan hati (Wiana,2009.38).

Terkait dengan banten pamali yang terdapat di Ubud sampai saat ini masyarakat Ubud masih konsisten dalam menyelenggarakan setiap upacara khususnya upacara mecaru dengan banten pamali. Banten pamali mengikuti rangkaian upacara mecaru. Menurut lontar Mpu Lutuk Banten caru dan Pupulan Indik Caru lan Tawur banten pamali digunakan pada upacara -upacara yang lebih besar. Namun, masyarakat Ubud setiap enam bulan sekali atau setiap piodalan diiringi dengan mecaru maka banten pamali ini juga menyertai.Berdasarkan hasil penelitian terungkap bahwa isi dan susunan banten pamali tersebut sebagai berikut. Pertama disiapkan sok besek/tempeh /baki sebagai tempatnya, berikut disusun taledan (sejenis jejahitaan yang bentuknya segi empat), cawu nasi sasah, kacang saur, ikannya lindung, capung, katak, balang,klopakan tiyingdan dedaunan seperti daun gegirang jajan/rakaraka, buah seperti pisang,bungsil (buah kelapa yang masih muda), clebingkah (pecahan genteng yang diisi dengan tapak dara), mengkudu terakhir diisi dengan canang sari. Untaian tersebut sejalan dengan Bangli, (2006.104)pamangguhan pamali agung isinya nasi sokan, be karangan, boki metumpuk tapis,celebingkah 5 tebih merajah kaya iki..SANG BANG TANG ANG ING, malih mapengampinan don dapdap, don temen,don kawasan, don gegirang,magenah manca desa,ngrajah celebingkah antuk pamor. Di dalam Pupulan Indik Caru lan Tawur juga disebutkan pamangguh pamali yang isinya hampir sama tetapi di lontar ini yang membedakan adalah don biah dan buahnya bluluk dari pohon enau(Anom Ida Bagus.64).Berdasarkan hasil penelitian dan dari salinan lontar Mpu Lutuk BantenCaru serta salinan lontar pupulan Indik Caru lan Tawur berisi tentang celebingkah yang diisi tapak dara dengan pamor. Tapak dara benbentuk horizontal dan vertical yaitu hubungan ke atas dan ke samping. Hubungan ke atas yaitu dengan Sang pencipta melalui sebuah banten sebagai media atau alat karena manusia masih mempunyai keterbatasan. Tuhan disimbolkan dan diwujudkan sesuai kemampuan pikiran manusia berupa banten dengan harapaan mencapai tujuan. Demikian juga hubungan ke samping agar terjadi keharmonisan dengan makhluk hidup lainnya seperti adanya hari Tumpek Wariga. Tumpek Wariga yaitu penghormatan kepada tumbuhtumbuhan sebagai rasa terimakasih manusia seharusnya pada hari tumpek wariga umat Hindu menanam pohon kembali agar terjadi keseimbangansehingga alam menjadi lestari.Tapak dara yang memberi makna keseimbangan dalam menjalani hidup. Dalam banten tersebut juga dilengkapi dengan buah mengkudu memberikan penegasan atau penyempurnaan bahwa dalam hidup haruslah seimbang, dengan menghilangkan mala atau kekotoran dalam diri yaitu pikiran, perkataan dan perbuatan. Mengkudu dalam banten pamali memilili fungsi yang religious yang mampu menetralisir keadaan yang tidak seimbang dalam tubuh manusia karena mengkudu salah satu khasiatnya adalah 

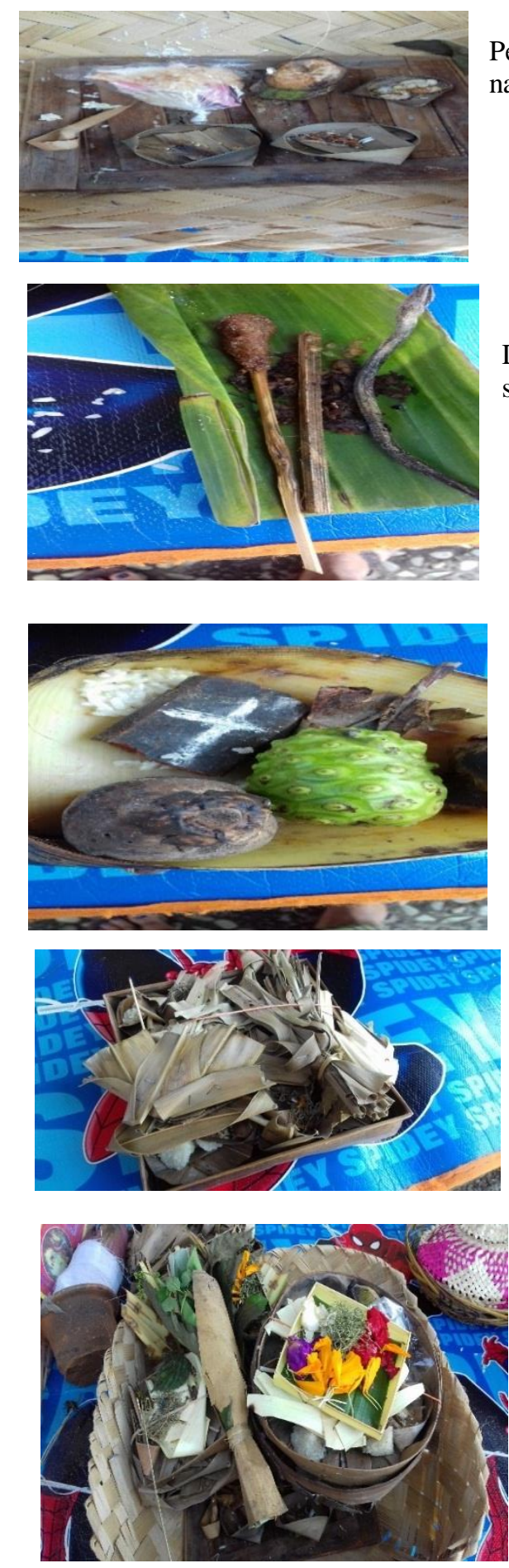

\section{c. Fungsi Mengkudu Dalam Banten Pamali Pada Upacara Mecaru}

Pertama sok besek diisi sebuahtaledan dengan nasi,kacang saur,pisang dan raka-raka

Daun pisang diisi dengan sate,lindung,capung.Katak semuanya diguling

Ketiga kelopak pisang diisi denganCelebingkah(tapak dara) mengkudu, bungsil

Sorohan alityaituSebuah jejahitan yang terdiri atasPeras, tulung, sayut dan lis amu-amuan

Kelima Banten pamali yang sudah jadilengkap dengandongegirang,don dapdap,don temen yang dibungkusdengan kelopak tiying dan sebuah canang sari.
Berdasarkan hasil penelitian fungsi mengkudu dalam banten pamali pada upacara mecaruadalah berfungsi religius 
yaitu sebagai persembahan dan fungsi kesehatan yaitu tubuh menjadi segar/bugar melalui minum minuman mengkudu yang dibuat dalam bentuk rujak air dan loloh. Dari uraian itu dapat dibedakan menjadi dua sebagai berikut.

\section{(1). Fungsi religius}

Fungsi religius adalah suatu keyakinan yang dilakukan oleh masyarakat Bali khususnya yang beragama Hindu melalui sebuah upacara dengan persembahannya berupa banten.Dengan keyakinan yang kuat itu akan memberikan vibrasi yang positif. Demikian juga segala penyakit yang dialami tidak hanya bisa disembuhkan oleh seorang dokter, dukun/balian akan tetapi melalui pebayuhan, pelukatan dengan media banten sakit itu dapat disembuhkan. Masyarakat Bali khususnya yang beragama Hindu bila sakit yang tidak kunjung sembuh, setelah ke dokter berkali- kali juga sakitnya tidak sembuh, kemudian pergi ke Balian/dukun. Setelah berobat ke Balian didiagnose sakitnya bukan karena medis tetapi ada factor lain seperti sakit niskala.Masyarakat di Bali masih mempercayai dengan adanya sakit yang diakibatkan oleh sekala maupun niskala. Yang dimaksud dengan sakit secara sekala yaitu penyebab sakit yang tampak, nyata dan berwujud, misalnya kena pisau, pilek karena kehujanan, patah tulang karena jatuh. Penyakit yang disebabkan oleh kausa niskala yaitu penyebab sakit yang tidak tampak seperti badan bengkak secara tibatiba tidak diketahui penyebabnya, kulit pipi sebelah tertarik ke atas sehingga bibir, mulut menjadi bengor tanpa sebab dan berbagai penyakit lainnya (Nala.1993.2). Penyakit yang disebabkan oleh kausa niskala ini diobati atau dilakukan penebusan dengan melukat atau mebayuh melalui sebuah sarana yaitu banten.

\section{(2) Fungsi Kesehatan}

Menurut Ayurweda mala atau kekotoran itu adalah hasil buangan, limbah tubuh atau ekskreta dari proses metabolism tubuh. Mala ini dapat dibagi atas 5 bagian besar yang berupa :

1. Sakrt : tinja, tahi/berak
2. Mutra : berupa air kemih/kencing

3. Sveda : keringat

4. Artava : darah haid setelah menginjak remaja dewasa

5. Stanya : berupa air susu terjadi setelah melahirkan

Jadi kelima mala ini harus dibuang, jika tidak maka akan menimbulan suatu penyakit. Di dalam Kitab Sushruta sutra stana 15 disebutkan sebagai berikut. Samadhosa samaagnishcha, sama dhatu malakriya, prasannaatmendriya manah, svasthya ityabhidhiyate. Yang artinya sehat menurut ayurweda adalah seimbangnya tri dosha, seimbang agni/enzim, pencernaan, dhatu/jaringan tubuh, mala/limbah dan mengontrol indriya serta pikiran. Berdasarkan uraian tersebut bahwa dengan menggunakan mengkudu sebagai rujak air, loloh yang menjadi kebiasaan orang tua di zaman dahulu menyebabkan badan terasa segar dan bugar. Bahkan juga dikatakan dapat mengatasi rasa nyeri. Mengkudu adalah buah yang berkhasiat obat. Buah mengkudu yang digunakan dalam banten pamali merupakan ajaran secara simbolis bagaimana agar manusia menjaga kesehatannya dengan memakan atau meminum minuman sehat yang berasal dari tumbuhan /tanaman yang berkhasiat obat. Orang tua zaman dahulu sudah tahu bahwa mengkudu itu adalah buah yang dapat menyehatkan tubuh namun, tidak mengetahui kandungan yang terdapat pada mengkudu tersebut. Secara tradisional orang tua di zaman dahulu sudah mengenal tanaman yang berkhasiat untuk kesehatan.Contoh tibah digunakan sebagai loloh yaitu untuk mengatasi maag, gastristis yaitu: buah tibah,kerikan kulit jeruk jeruti,rimpang kunir,madu. Bahan tersebut digerus halus, disaring ditambah dengan madu(Nala.1993.254).

\section{Simpulan dan Saran}

a. Simpulan

Berdasarkan uraian tersebut di atas maka penelitian ini dapat ditarik suatu kesimpulan sebagai berikut.

1. Mengkudu sebagai sarana dalam banten pamali pada upacara mecaru 
adalah karena mengkudu tanaman yang mempunyai khasiat obat

2. Tata cara menyusun banten pamali sebagai berikut : 1)sok besek diisi sebuah taledan dengan nasi, kacang saur, pisang dan raka-raka,2)Daun pisang diisi dengan sate, lindung, capung ,katak semuanya diguling,3) kelopak pisang diisi dengan celebingkah yang ditandai dengan tapak dara,bungsil,mengkudu, 4)Sorohan alit dan 5)Banten pamali yang sudah jadi.

3. Fungsi mengkudu dalam banten pamali pada upacara mecaru yaitu fungsi religius dan fungsi kesehatan.

\section{b. Saran}

Berdasarkan pembahasan dan simpulan di atas maka dapat disarankan sebagai berikut.

1. Kepada masyarakat di Ubud agar membudidayakan mengkudu,karena mengkudu sebagai salah satu sarana dalam membuat banten khususnya banten pamali.

2. Kepada masyarakat luas agar ada penelitian lebih lanjut tentang bantenbanten yang menggunakan sarana/bahan tanaman yang berkhasiat obat

3. Kepada generasi muda agar mempelajari jeni-jenis banten sebagai salah satu mengajegkan budaya Bali.

\section{Daftar Pustaka}

Ananda Kusuma Sri Reshi,1986. Kamus Bahasa Bali.CV.Kayumas.

Anonim, 2005. Kamus Istilah Agama Hindu.Program Pengembangan Lembaga Lembaga Sosial Keagamaan Dan Lembaga Pendidikan Agama.

Anonim, 2005. Kamus Bali Indonesia.Balai Bahasa Denpasar. Pusat Bahasa Departemen Pendidikan Nasional.Cetakan Pertama.

Anonim, 2010. Canang Sari Dharmasmrti Mengenang Bhakti Prof.Nala.Penerbit Widya Dahrma Denpasar.Dicetak oleh percetakan
Mabhakti. ISBN: 978-602-967545-0

Anom Ida Bagus,2003. Diktat Pupulan Indik Caru Lan Tawur

Bagus Loren,2005. Kamus Filsafat.Penerbit PT Gramedia Pusaka Utama Jakarta. Cetakan keempat.

Bangli I.B, 2006. Warnaning Sesayut lan Caru.Penerbit Paramita Surabaya

Candra I.B, 2016. Tesis. Pasca Ilmu Agama \& Kebudayaan UNHI

Gorda,2004.Membudayakan Kerja Berdasarkan Dharma. Penerbit Pusat Kajian Hindu Budaya Dan Perilaku Organisasi Sekolah Tinggi Ilmu Ekonomi Satya Dharma Singaraja

Hakimah Ainun Indy,2013. 150 Makanan \& Minuman Anti Sakit Berkhasiat Obat. Penerbit Syura Media Utama. Cetakan pertama

Mantra. 1997.Bagawadgita Proyek Peningkatan Sarana dan Prasarana Kehidupan Beragama Tersebar di 9 (sembilan) Dati II.

Nala Ngurah.2001. Ayurveda Ilmu kedokteran Hindu I. Penerbit Upada Sastra Denpasar. -,1993.Usada Bali.Penerbit PT Upada Sastra Denpasar

Peter Salim, Yenny Salim. 2002. Kamus Bahasa IndonesiaKontemporer, Edisi Ke Tiga.

Prime. 2006. Tri Hita Karana Ekologi Ajaran Hindu.

Sayuthi Ali,2006. Metodologi Penelitian Agama. PT Raja Grafindo Persada Jakarta.

Sudarsana, I.B tt. Himpunan Tetandingan Upakara Yadnya. Edisi ketiga (revisi)

Sugiyono,2013.Metode Penelitian Kuantitatif Kualitatif Dan $R \& D$. Cetakan ke-18. Penerbit Alfabeta Bandung

Suwandi Monica,tt.Khasiat Jus Buah dan Sayuran. Penerbit Jawara

Triguna, 2000. Teori Simbol. Penerbit Widya Dharma 2011.Startegi Hindu.Penerbit Pustaka Jurnal Keluarga. Cetakan Pertama 
Wiana,2007.Tri Hita Karana Menurut Konsep Hindu.Paramitha Surabaya. -,2006. Beragama Bukan Hanya Di Pura. Penerbit Yayasan Dharma Narada.Cetakan kedua

\section{Lontar}

Pucuk,tt Empu Lutuk Banten Caru. 